\title{
SIMULATION OF THE CONTACT TEMPERATURE IN THE CYLINDRICAL PLUNGE GRINDING PROCESS
}

\author{
Yurii SYZYI, Oleksandr USHAKOV, Serhii SLIPCHENKO, Yevheniia BASOVA, Maryna IVANOVA \\ National Technical University “Kharkiv Polytechnic Institute”, Department of Technology of Mechanical \\ Engineering and Metal-Cutting Machine Tools, 2, Kyrpychova str., 61002, Kharkiv, Ukraine \\ e-mail: e.v.basova.khpi@gmail.com
}

\begin{abstract}
The intensifying of the manufacturing process and increasing the efficiency of production planning of parts are the first-priority task in modern manufacturing. The use of various methods for controlling the cutting force and temperature in cutting zone under cylindrical infeed grinding and studying its impact on the quality and accuracy of parts machining can improve machining efficiency. The peculiarity of the work is to the proposal to consider a fast-moving source like a heat source in the plunge grinding process. Based on the Peclet analysis, the further development of the method for calculating the allowance removed at each workpiece revolution by optimizing the cylindrical plunge grinding cycle parameters has been justified. The methodology for determining the optimal parameters of a cylindrical plunge grinding cycle, which based on a simulation of the dynamics of such a process represented by a three-mass model of a 3M151 circular grinding machine has been used in research. The practical value of the study lies in studying the ways of improving the grinding performance of the parts by intensifying cutting modes and optimizing the structure of machining cycles.
\end{abstract}

Keywords: thermophysics of the grinding process, contact zone of the grinding wheel and the workpiece, grinding process dynamics, surface quality, defective layer

\section{INTRODUCTION}

Among the main and priority tasks for the modern competitive manufacturing enterprises, the active search for optimal technological solutions in the field of intensification of technological processes is highlighted $[1,2]$. Priority is given to improving the efficiency of manufacturing critical and expensive parts, which require abrasive processing methods. Such parts are subject to high requirements in terms of roughness, dimensional accuracy, etc. These requirements are fulfilled by machining these parts using universal and special grinding machines with the use of special tooling and fixture. At the same time, it is necessary to note the sharply increased requirements for technical and economic indicators of grinding operations, especially in automated and robotic production. Thus, in the context multiproduct manufacture, should be taken into account the quality criteria [3, 4] and energy efficiency [5, 6], equipment [7, 8] and tooling $[9,10]$ capabilities, processing modes $[11,12]$, the design and technical parameters of the parts [13-15], the properties of materials and coatings [16-20].

The performance and cost of cylindrical plunge grinding operations for parts are largely determined by the selected parameters of the grinding cycle and the method of managing this cycle. Besides, grinding parts, the optimal machining cycle can be determined by the minimum machine time, as defined by the speed of the cross-infeed traverse and the amount of allowance. Increasing the crosstraverse leads to an increase in the cutting force components, which triggers an increase in the elastic strain of the elements of the technological system "workpiece-grinding wheel-grinding machine".

A large influence on the accuracy and quality of the ground surface is exerted by the temperature in the contact zone of the workpiece and the grinding wheel. The depth of the defective layer on the surface of the workpiece directly depends on the temperature in the contact zone, which in turn is determined by the cutting conditions.

Thus, the search for optimal cutting conditions, providing, on the one hand, maximum productivity, and, on the other hand, the minimum depth of the defective layer, is an urgent task.

\section{LITERATURE REVIEW}

Two basic approaches have been applied in the study of the thermal physics of grinding when the workpiece heating sources are primarily considered: the surface area of contact of the grinding wheel with the workpiece [21-24]; the total thermal effect in the case of single abrasive grains cutting [25-30]. 
The thermophysics of the grinding process is also reflected in the research citations $[31,32,33]$.

In article [34] was shown to the development of a mathematical model of the combined grinding process. Based on the main provisions of the theory of abrasive processing, authors [34] dependencies are developed to calculate the probability of removal of the material at any point in the contact zone taking into account several simultaneous processes of formation. The complexity of the physical processes of surface formation connected with a large number of technological factors, with the help of which the parameters of this process can be changed, is shown [34]. The model takes into account the peculiarities of the stochastic nature of the abrasive processing process and the interaction of additional physical processes and technological factors. In paper [35] authors were proposed a model is based on the probabilistic approach and it allows calculating the value of the bond layer removed with erosive discharges and predict the state of the technological system at any moment. In paper [36] by authors was proposed improvement the contact performance properties, by submitting presentation of optimization of flat grinding of titanium parts by following two parameters: the relative bearing length of the profile and the relative bearing part of the parts' surface that allow assessing the quality of the surface at the microand macro-scale. The Bogutsky, V. and all shown that during the grinding of complex profile blades of metal cutting tools from tool steels, unfavorable thermodynamic conditions are created in the cutting zone and, as a result, grinding burns and cracks occur on the surface of the polished workpiece [37]. The method of calculating the profile of the discontinuous surface of the grinding wheel presented in the article makes it possible to determine its geometric parameters taking into account the wear resistance of the grinding wheel and the heat stress of the process of treatment [37]. In paper [38] a vitrified bond $\mathrm{CBN}$ point grinding wheel with coarse grinding area slope angle $\theta$ was presented. The theory of grinding heat generation and distribution and infrared temperature measurements were submitted. The effects of different grinding parameters were generalized. In the paper [39], the authors emphasized that a massive amount of heat is generated during the high-efficiency grinding process, which leads to a serious burnout problem that limits the increase of the material removal rate. An oscillating heat pipe grinding wheel that is a combination of a grinding wheel and OHPs was proposed by Qian, N. and all. The results of researches on temperature variations during flat peripheral grinding are presented in Smirnov's V.A. and Repko's A.V. paper [40]. In the article, a nonlinear two-dimensional thermophysical grinding model is suggested. The researchers claim that the proposed thermophysical model makes it possible to predict with high accuracy the temperature variations during grinding by the wheel periphery [41]. In paper [42] the result of the investigation of thermal processes in the course of magnetorheological polishing has been carried out. Physical and mathematical description of heat transfer from a treated surface to a polishing tool is given with consideration of the specifics conditions [42]. An analytical estimate of the thermal state of a magnetorheological abrasive tool and a treated workpiece surface is given [42]. A procedure to calculate the temperature in grinding massive, thin, and wedge-shaped parts with account taken of the geometric and thermophysical parameters of the tool and the treated part, and also of cutting regimes has been presented by Dement and other [43]. In the paper, a relationship between the temperature in the grinding zone and the regimes of treatment which makes it possible to control the quality of the surface layer of massive, thin, and wedge-shaped plates from hard-to-machine steels has been estimated [43]. In scientific works [44, 45], the surface being processed is presented as a set of adiabatic rods, which allows the authors to solve the problem of heat balance and improve the surface quality according to the temperature criterion. In the present work, the continuous surface area of the grinding wheel with the surface being machined is taken as the heating source of the workpiece. This approach is quite fully developed in paper [23]. However, the main difference between the present work is the representation of the heat source not in the form of a plane that moves along the surface of the half-space, but in the form of a fast-moving one. The possibility of such a substitution is proved by the Peclet criterion analysis [26] (1):

$$
\mathrm{P}_{\mathrm{e}}=\frac{\mathrm{V}_{\mathrm{z}} \cdot L}{a} \leq 8 \div 10,
$$

where $L-$ the heat source size in the direction of its movement; $a$ - thermal diffusivity of the workpiece material.

Application of the concept of "fast-moving heat source" made it possible to obtain the dependence $T(\tau, x)[46]$ by integration over time, i.e. taking into account the surface of the workpiece in the heat source and outside it. This, in turn, made it possible to take into account the different heat transfer from the surface of the workpiece when it is in the contact zone and outside it. In the present paper, when optimizing the parameters of the cylindrical plunge grinding cycle, the allowance for the workpiece removed at each turn is calculated based on the formulas obtained in research [46], in which the so-called "generalized static characteristic of the grinding process" is used (2):

$$
\mathrm{K}_{g r}=\frac{C_{p}}{j+C_{p}},
$$


where $C_{p}$ - grinding process rigidity; $j$ - rigidity of the system "workpiece - abrasive wheel - metalcutting machine".

The rigidity $j$ is determined experimentally, as shown in research [46]. And $C_{p}$ is determined based on the experimental formula for calculating $P_{z}$ from the grinding conditions with the transition to $P_{y}-$ the radial component of the grinding force and its linearization concerning the grinding depth $h$, i.e. getting dependency (3)

$$
P_{y}=C_{p} \cdot h \text {. }
$$

\section{METHODS FOR SOLVING THE \\ PROBLEM OF THE OPTIMAL \\ PARAMETERS DETERMINING OF A \\ CYLINDRICAL PLUNGE GRINDING CYCLE}

The methodology for determining the optimal parameters of a cylindrical plunge grinding cycle (CPGC) is based on a simulation of the dynamics of a CPGC represented by a three-mass model of a 3M151 circular grinding machine. Based on it, formulas for calculating the allowance taken during grinding at each phase of the cycle using the experimental dependence of the grinding force $\mathrm{Pz}$ on the grinding conditions (processes, wheel characteristics, dressing conditions) and the generalized static CPGC characteristic are obtained.

The amount of allowance necessary for removal, i.e. the value of the workpiece defective surface layer is determined based on the analytically obtained dependence $T(\tau, x)$ for a fastmoving heat source with programming the integration limits over time. This takes into account the differing intensity of heat transfer from the workpiece in the contact zone with the grinding wheel and outside contact zone.

The heating of the grinded workpiece $T(\tau, x)$, as a function of $x$ - the distance from the surface in the radial direction and $\tau-$ the time counted from the moment the workpiece surface enters the contact zone with the grinding wheel [46] is calculated by the formula (4):

$$
\begin{aligned}
& \frac{\exp \left(-\frac{\mathrm{x}^{2}}{4 \cdot a \cdot(\tau-t)}\right)}{\sqrt{\tau-t}} . \\
& T(\tau, \mathrm{x})=\frac{q \cdot \sqrt{a}}{\lambda \cdot \sqrt{\pi}} \int_{0}^{i f\left(\tau<\tau_{1}, \tau, \tau_{1}\right)} \cdot\left[1-\frac{\operatorname{if}\left[\tau \leq \tau_{1}, \alpha_{1}, \alpha\left(1-\frac{\tau}{\tau_{2}}\right)\right]}{\lambda}\right. \\
& \cdot \sqrt{\pi \cdot a(\tau-t)} \cdot \\
& \cdot\left[1-\operatorname{erf}\left[\begin{array}{l}
\frac{x}{\sqrt{4 \cdot a \cdot(\tau-t)}}+ \\
\operatorname{if[}\left[\tau \leq \tau_{1}, \alpha_{1}, \alpha\left(1-\frac{\tau}{\tau_{2}}\right)\right] \\
\left.+\frac{\sqrt{a \cdot(\tau-t)}}{\lambda}\right]
\end{array}\right],\right.
\end{aligned}
$$

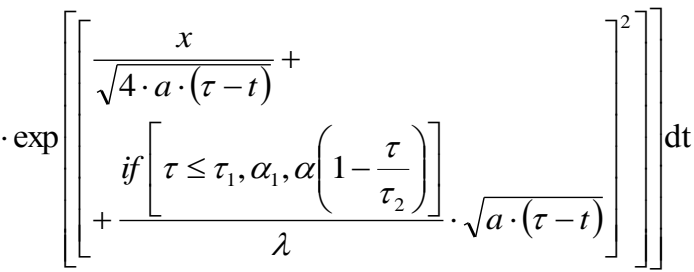

(4)where $q=\frac{P_{z} \cdot V_{\kappa}}{L \cdot B} \cdot \beta$ - heat flux density, $\frac{J}{\mathrm{sm}^{2} \cdot \mathrm{sec}} ; P_{z}-$ peripheral grinding force, $\mathrm{N} ; V_{\kappa}-$ grinding wheel peripheral speed, $\mathrm{m} / \mathrm{sec} ; a$ - thermal diffusivity, $\mathrm{mm}^{2} / \mathrm{sec} ; \lambda-$ heat conduction coefficient, $\frac{J}{\mathrm{~mm} \cdot \mathrm{sec} \cdot \mathrm{deg}} ; \tau-$ temperature observation time; $(\tau-t)$ - heat propagation time from the moment $t$ of the occurrence of the heat pulse to $\tau$ - observation time; $\tau_{1}$ - heating source action time, sec; $\tau_{2}$ - the time of workpiece processing, sec; $\alpha_{l}$ - heat transfer coefficient in the heat source, $\frac{J}{\mathrm{~mm}^{2} \cdot \mathrm{sec} \cdot \mathrm{deg}} ; \alpha-$ heat transfer coefficient outside the heat source; "if" conditional operator, with the help of which the solution of the problem of determination $\mathrm{T}(\tau, \mathrm{x})$ in the heat source and outside it is programmed.

The grinding circumferential force $P_{z}$ is calculated from the experimental dependence [46]:

$$
P_{z}=2,254 \frac{\sigma_{t}^{0,342} \cdot H^{0,258} \cdot V_{p}^{0,945} \cdot B}{Z^{0,051} \cdot S^{0,073} \cdot S_{p r}{ }^{0,073} \cdot t_{p r}{ }^{0,026}}, \mathrm{~N}
$$

where $\sigma_{t}-$ tensile strength of the workpiece material at a temperature of $600{ }^{\circ} \mathrm{C} ; \mathrm{H}$ - the meter readings “Звук - 202" (natural frequency $\mathrm{kHz}$, GOST 25961-83); $Z$ - grain size; $V_{p}$ - infeed rate, $\mathrm{mm} / \mathrm{min} ; S-$ the peripheral speed of workpiece rotation, $\mathrm{m} / \mathrm{min} ; S_{p r}$ - the longitudinal speed with the impregnated diamond tool, $\mathrm{mm} / \mathrm{min} ; t_{p r}-$ the depth of dressing, mm.

The $\operatorname{arc}$ length contact $\mathrm{L}$ is calculated by the formula [28, 31]: 


$$
L=\sqrt{D_{e} \cdot h},
$$

where $D_{e}=\frac{D_{w}}{1+\frac{D_{w}}{d_{z}}}$ the effective grinding wheel diameter, mm; $D_{w}$ - grinding wheel diameter, mm; $d_{z}$ - workpiece diameter; $h$ - grinding depth (lateral feed per workpiece revolution), $\mathrm{mm}$.

The fraction of heat generated during grinding entering the workpiece is taken into account by the input coefficient $\beta[23,46]$ :

$$
\beta=\frac{1}{1+h \sqrt{\frac{4 \cdot V_{z} \cdot 10^{3}}{60 \cdot L \cdot a \cdot \pi}},}
$$

Period of applicability of the heat source $\tau_{1}$, and the workpiece processing time $\tau_{2}$ are calculated by (8):

$$
\tau_{1}=\frac{L \cdot 60}{V_{z} \cdot 100} ; \quad \tau_{2}=\frac{\pi \cdot d_{z} \cdot 60}{V_{z} \cdot 100} .
$$

To calculate the number of revolutions in the phases of roughing and finishing grinding, it is necessary to use the following formulas for calculating the removed allowance for the workpiece radius [46]:

i. for grinding on rough feed $S_{10}$

$$
\prod=\sum_{i=1}^{n_{2}}\left[S_{10}\left(1-K_{g r}^{i}\right)\right] \text {; }
$$

ii. for grinding in fine feed $S_{0}$

$$
\prod_{1}=\sum_{i=1}^{n_{1}}\left[S_{0}\left(1-K_{g r}^{i}\right)+S_{10} \cdot K_{g r}^{i}\right] .
$$

In these formulas, $n_{1}$ and $n_{2}$ are the numbers of revolutions of the workpiece during the finishing and rough grinding phases, respectively.

The calculation of the maximum workpiece revolutions number necessary to remove the allowance $\boldsymbol{\Pi}$ for the CPGC operation with the removal of the defective layer formed by grinding with rough feed $S_{10}$ is as follows:

i - selectable $S_{10}$;

ii - the depth of the defective layer $H_{d}$ is calculated;

iii - from (10), find the selection $n_{1}$ so that the allowance $\boldsymbol{\Pi}_{1}$ removed at the final feed $S_{0}$ is equal to $H_{d}$;

iv - the allowance for the rough feed of the previous finishing feed will be equal to $\boldsymbol{\Pi}-\boldsymbol{\Pi}_{1}$ and $n_{2}$, which is necessary for its removal could be found using (9);

$\mathrm{v}$ - the total minimum number of revolutions $n=n_{1}+n_{2}$ and determines the optimum grinding operation.

\section{RESULTS AND DISCUSSION}

The study of the CPGC operation as applied to grind a cylindrical surface $\varnothing 100 f 7\left(\begin{array}{l}-0,036 \\ -0,071\end{array}\right)$ along the axis $B=40 \mathrm{~mm}$ long was performed. In the research, the optimal two-stage CPGC with peripheral workpiece rotation speeds $S=35 \mathrm{~m} /$ min and feed $S=100 \mathrm{~m} / \mathrm{min}$ are compared in terms of productivity.

The optimal CPGC is the cycle that providing the part heating no higher than $T_{\text {lim }}=490{ }^{\circ} \mathrm{C}$ and the minimum number of workpiece rotations.

To calculate the force $P_{z}$ according to formula (5), we assume that grinding is performed with a wheel 24A16HCM1K. Therefore, for the hardness of the circle CM1, the readings of the «Звук-202» device are $H=1.38$.

Hardened steel $40 \mathrm{X}$ is grinded and therefore $\sigma_{B}=22 \mathrm{kgf} / \mathrm{mm} 2$, the grain size of the selected wheel is $z=16$. Dressing process: $S_{p r}=150 \mathrm{~mm} / \mathrm{min}$, $t_{p r}=0.01 \mathrm{~mm}$. The values of the coefficients are $\alpha_{1}=0, \quad \alpha_{2}=0,017 ; \quad \frac{J}{\mathrm{~mm}^{2} \cdot \mathrm{sec} \cdot \mathrm{deg}}, \quad$ which corresponds to the cooling of the workpiece by water-based irrigation liquid [26].

The heat transfer in the contact zone, taken into account by the coefficient $\alpha$, is extremely small since the cooling fluid practically does not enter the contact zone and therefore $\alpha_{1}$ can be taken equal to zero.

The values of $a$ and $\lambda$ for steel $40 \mathrm{X}$ are as follows [28]: $\quad a=6,7 \quad \mathrm{~mm}^{2} / \mathrm{sec}$; $\lambda=0,0339 \frac{J}{\mathrm{~mm} \cdot \mathrm{sec} \cdot \mathrm{deg}}$. Thus, there is all the data for calculating $T(\tau, x)$, which means that for calculating the value of the defective layer of the workpiece, i.e. layer heated above $490{ }^{\circ} \mathrm{C}$. Changing $V_{p}$ in formula (4) and sorting out the value of $x$, we can find its value $x_{i}$ such that the maximum value of $T\left(\tau, x_{i}\right)$ is equal to $490{ }^{\circ} \mathrm{C}$ (Fig. 1).

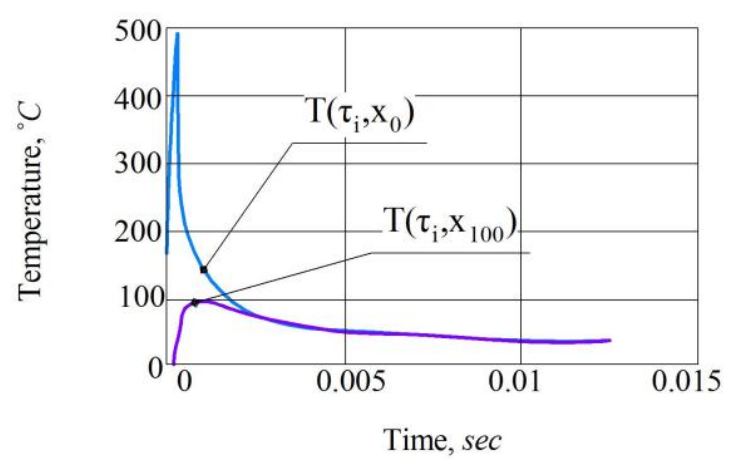

Fig. 1. Results of determination of $x_{i}$ value, for which value of function $T(\tau, x)$ will be maximum $\left(T_{\max }=490^{\circ} \mathrm{C}\right)$

Figure $2 a$ shows a fragment of the MathCAD program for determining the speed $V_{p}$, denoted as 
$V_{\text {pop }}$, that provides the maximum temperature on the surface $T_{\max }=490^{\circ} \mathrm{C}$.

So for $S=100 \mathrm{~mm} / \mathrm{min}$ the vector of discrete values $V_{p}=(1.1,1.5,2,3,4,4.5)^{T}$ have been received respectively the vector of the defective layer depth $H_{d}$, i.e., the layer heated above $490{ }^{\circ} \mathrm{C}$, $H_{p}=(0,0.001,0.021,0.039,0.053,0.06)^{T}$.

The dependence $H_{d}\left(V_{p}\right)$ is approximated by a polynomial of the $2^{\mathrm{d}}$ degree, as is done when planning experiments and it is denoted as $\mathrm{H}_{\mathrm{d}}\left(\mathrm{V}_{\mathrm{pop}}\right)$ on Fig. $2 a$.

The vector $V_{p}$ is represented by the matrix $\mathbf{X}$ of the experimental conditions, and the vector $H_{p}$ is represented by the vector $H_{d}$ of the experimental results, and by the formula $\mathbf{B}=\left(\mathbf{X}^{\mathbf{T}} \cdot \mathbf{X}\right)^{-1} \cdot\left(\mathbf{X}^{\mathbf{T}} \cdot \mathbf{Y}\right)$, compute the coefficients of the polynomial of the second degree. The vector $\mathbf{Y}$ is compared with the vector $\mathbf{Y} 1$ - calculated by the model of $H_{p}$ values. It can be seen from this comparison that the obtained model equation describes the $H_{d}\left(V_{p}\right)$ dependence well. The dependence $H_{p}\left(V_{p}\right)$ was obtained at $S=35 \mathrm{~m} / \mathrm{min}$ and it is denoted as $\mathrm{H}_{\mathrm{d}}\left(\mathrm{V}_{\text {pop }}\right)$ in the Fig. $2 a$. The resulting dependence is the polynomial $H_{1 d}\left(V_{p}\right)$. The graphical comparison (Fig. 2b) of dependences $H_{d}\left(V_{p}\right)$ and $H_{1 d}\left(V_{p}\right)$ shows that the depth of the defective layer at $S=100 \mathrm{~m} / \mathrm{min}$ is significantly less than at $S=35 \mathrm{~m} / \mathrm{min}$ when $V_{p}$ varies in the range of its possible values on the 3M151 grinding machine.

Since in the formulas (9) and (10), the allowance is a function of $S_{0}, S_{10}$, it is necessary to have formulas for calculating the depth of the defective layer $H_{d}$ as a function of the transverse feed per revolution.
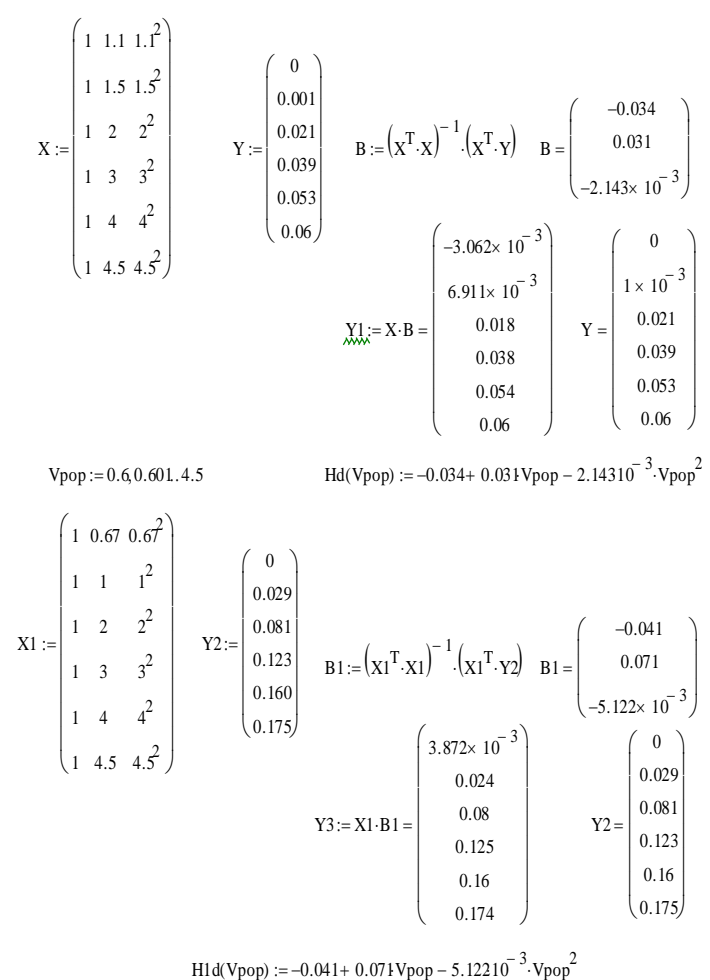

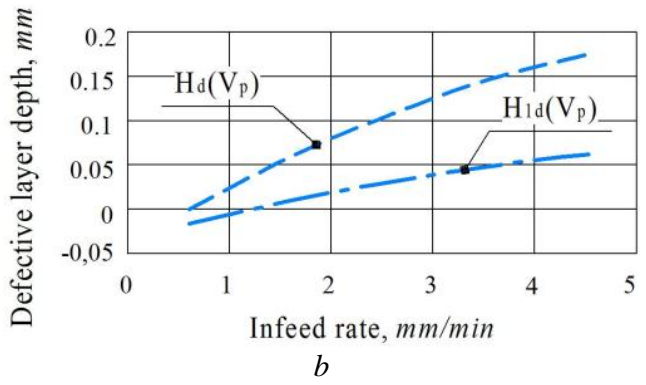

Fig. 2. Modelling of the dependence of the defective layer depth on indeed rate: $a$ - the procedure for obtaining $\mathrm{H}_{\mathrm{d}}\left(\mathrm{V}_{\mathrm{p}}\right)$ and $\mathrm{H}_{1 \mathrm{~d}}\left(\mathrm{~V}_{\mathrm{p}}\right)$ in MathCAD; $b$ - the approximation of the dependences $H_{d}\left(V_{p}\right)$ and $\mathrm{H}_{1 \mathrm{~d}}\left(\mathrm{~V}_{\mathrm{p}}\right)$

for $S=35 \mathrm{~m} / \mathrm{min}$ and $S=100 \mathrm{~m} / \mathrm{min}$ respectively

For this, the transition to $V_{\text {pop }}$ vectors was made $S_{0}=V_{p} \cdot \frac{\pi \cdot d_{z}}{V \cdot 100}$, and then, similarly to the $H_{d}\left(V_{p}\right)$ dependences, the $H_{d 1}\left(S_{0}\right)$ dependences were obtained for $S=100 \mathrm{~m} / \mathrm{min}$ and $H_{d 2}\left(S_{0}\right)$ for $S=35 \mathrm{~m} / \mathrm{min}$. All necessary calculation results are shown in Fig. $3 a$.

It can be seen from Fig. 3,b that $H_{d 1}\left(S_{0}\right)$ and $H_{d 2}\left(S_{0}\right)$ there is minimal difference between each other, however, given that the workpiece revolution time at $S=100 \mathrm{~m} / \mathrm{min}$ is almost three times less than the revolution time of it at $S=35 \mathrm{~m} / \mathrm{min}$, we should expect the performance of a two-stage plunge grinding cycle with optimal combinations of $S_{0}$ and $S_{01}$ will be significantly higher at $S=100$ $\mathrm{m} / \mathrm{min}$ than at $S=35 \mathrm{~m} / \mathrm{min}$.

$$
\begin{aligned}
& \text { Vpop }:=\left(\begin{array}{llllll}
1.1 & 1.5 & 2 & 3 & 4 & 4.5
\end{array}\right)^{\mathrm{T}} \quad \mathrm{Hd}:=\left(\begin{array}{llllll}
0 & 0.001 & 0.021 & 0.039 & 0.053 & 0.06
\end{array}\right)^{\mathrm{T}} \mathrm{dz}:=100
\end{aligned}
$$

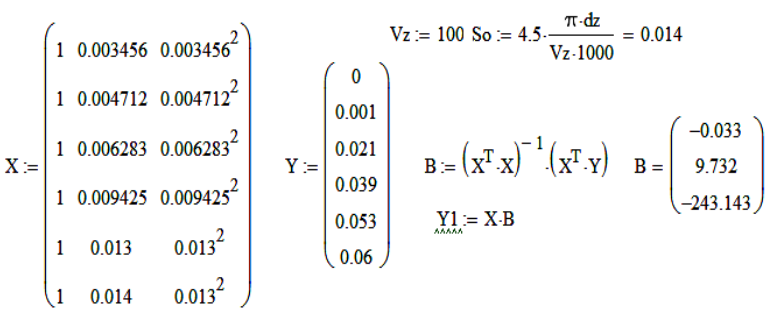

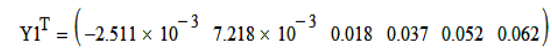

$$
\begin{aligned}
& \text { а)Коэфициенты В в зависимости } \mathrm{Hd}(\mathrm{So}) \text { гри } \mathrm{Vz}=100
\end{aligned}
$$

$$
\begin{aligned}
& \mathrm{So}:=4.5 \cdot \frac{\pi \cdot d z}{\mathrm{Vz} \cdot 1000}=0.04 \\
& \begin{array}{l}
\mathrm{X} 2:=\left(\begin{array}{ccc}
1 & 0.006014 & 0.006014^{2} \\
1 & 0.008976 & 0.008976^{2} \\
1 & 0.018 & 0.018^{2} \\
1 & 0.027 & 0.027^{2} \\
1 & 0.036 & 0.036^{2} \\
1 & 0.04 & 0.04^{2}
\end{array}\right) \quad \mathrm{Y} 3:=\left(\begin{array}{c}
0 \\
0.029 \\
0.081 \\
0.123 \\
0.160 \\
0.175
\end{array}\right) \quad \mathrm{B} 2:=\left(\mathrm{X} 2^{\mathrm{T}} \cdot \mathrm{X} 2\right)^{-1} \cdot\left(\mathrm{X} 2^{\mathrm{T}} \cdot \mathrm{Y} 3\right) \\
\mathrm{Y} 4:=\mathrm{X} 2 \cdot \mathrm{B} 2 \\
\text { б) Коэффрициенты в зависимости Hd(So) при Vz=35 }
\end{array}
\end{aligned}
$$

So: $=0.003,0.0031 . .0 .02 \quad \operatorname{Hd} 1($ So $):=-0.033+9.732 \cdot \mathrm{So}-243.143 \cdot \mathrm{So}^{2}$

$\mathrm{Hd} 2(\mathrm{So}):=-0.041+7.784 \cdot \mathrm{So}-60.725 \cdot \mathrm{So}^{2}$ 


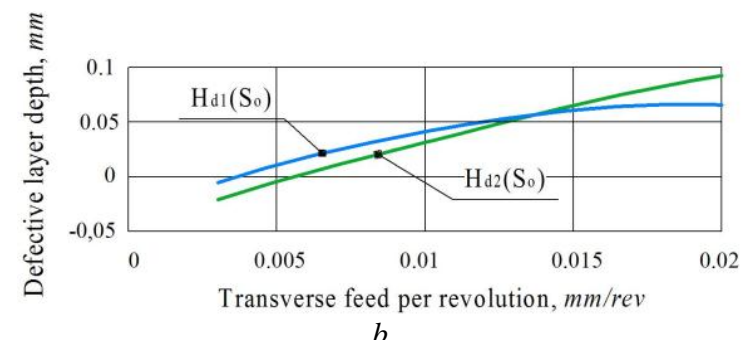

Fig. 3. Modelling of the dependence of the defective layer depth on indeed rate: $a$ - the procedure for obtaining $\mathrm{H}_{\mathrm{d} 1}\left(\mathrm{~S}_{\mathrm{o}}\right)$ and $\mathrm{H}_{2 \mathrm{~d}}\left(\mathrm{~S}_{\mathrm{o}}\right)$ in MathCAD; $b$ - the approximation of the dependences $\mathrm{H}_{\mathrm{d} 1}\left(\mathrm{~S}_{\mathrm{o}}\right)$ and $\mathrm{H}_{2 \mathrm{~d}}\left(\mathrm{~S}_{\mathrm{o}}\right)$

for $S=35 \mathrm{~m} / \mathrm{min}$ and $S=100 \mathrm{~m} / \mathrm{min}$ respectively

Assuming that $P_{y} \cong 2,5 P_{z}$ and going to (5) from $V_{p}$ to $h$ by the formula $V_{p}=\frac{h \cdot 1000 \cdot S}{\pi \cdot d}$, the radial component of the grinding force

$$
P_{y}=1,306 \cdot 10^{3} \frac{\sigma_{t}^{0,342} \cdot H^{0,258} \cdot S^{0,872} \cdot B}{Z^{0,051} \cdot S_{\mathrm{Pr}}^{0,073} \cdot t_{\mathrm{Pr}}^{0,026} \cdot d^{0,945}} \cdot h^{0,945} \text {. }
$$

Dependence (11) should be linearized concerning $h$, i.e. replace $h^{0,945}$ with $C \cdot h$, which is performed by the least-squares method in the range of variation of $h=(0,001-0,02) \mathrm{mm}$ and $C=1,262$ obtained.

Besides, it should be noted that in the model of the CPGC dynamic on the 3M151 grinding machine [46], the grinding depth has a dimension of meters, the equation (11) is converted to:

$P_{y}=1,306 \cdot 10^{3} \frac{\sigma_{t}^{0,342} \cdot H^{0,258} \cdot S^{0,872} \cdot B}{Z^{0,051} \cdot S_{\mathrm{Pr}}^{0,073} \cdot t_{\mathrm{Pr}}^{0,026} \cdot d_{z}^{0,945}} \cdot 1,262 \cdot 1000 \cdot h$

Consequently

$$
C_{P}=1,642 \cdot 10^{6} \frac{\sigma_{t}^{0,342} \cdot H^{0,258} \cdot S^{0,872} \cdot B}{Z^{0,051} \cdot S_{\mathrm{Pr}}^{0,073} \cdot t_{\mathrm{Pr}}^{0,026} \cdot d_{z}^{0,945}}
$$

and for $S=100 \mathrm{~m} / \mathrm{min}$ and the other parameters of equation (11) adopted above, it was obtained that $C_{p}=9,999 \cdot 10^{7} \mathrm{~N} / \mathrm{m}$, and for $S=35 \mathrm{~m} / \mathrm{min}$ $C_{p}=4 \cdot 10^{7} \mathrm{~N} / \mathrm{m}$.

The rigidity $j$ necessary for calculating $K_{g r}$ was obtained experimentally [46] and is equal to $3.17 \cdot 10^{7} \mathrm{~N} / \mathrm{m}$. Consequently: $K_{g r}=0.759$ for $S=100 \mathrm{~m} / \mathrm{min}$ and $K_{\mathrm{II}}=0.557$ for $S=35 \mathrm{~m} / \mathrm{min}$.

In Fig. 4 shows the calculation $n_{1}$ and $n_{2}$ when $S$ designated as $V_{Z}=100 \mathrm{~m} / \mathrm{min}$. The allowance $\boldsymbol{\Pi}$ according to its calculation and analytical definition [47] is $0.2 \mathrm{~mm}$ per radius. The final feed per revolution $S_{O}$ is defined and equal to $0.0035 \mathrm{~mm}$. The calculation formula is obtained (Fig. 3a) $H_{d}=-0.033+9.732 \cdot S_{10}-43.143 \cdot S_{10}^{2}$.

$$
\begin{aligned}
& \mathrm{j}:=3.17 \cdot 10^{7} \quad \underset{\mathrm{M}}{\mathrm{c}:=10.10^{7}} \quad \mathrm{k}:=\frac{\mathrm{c}}{\mathrm{j}+\mathrm{c}} \quad \mathrm{k}=0.759 \quad \mathrm{Vz}:=100 \quad \mathrm{dz}:=100 \\
& \text { Ï }:=0.2 \text { So }:=0.0035 \quad \mathrm{~S} 1 \mathrm{o}:=0.012 \mathrm{Hd}:=-0.033+9.732 \mathrm{~S} 1 \mathrm{o}-243.143 \mathrm{~S} 1 \mathrm{o}^{2} \\
& \begin{array}{c}
\text { Vpop }:=\frac{\mathrm{S} 1 \mathrm{o} \cdot \mathrm{Vz} 1000}{\pi \cdot \mathrm{dz}} \quad \mathrm{Vpop}=3.82 \quad \mathrm{Gt}:=22 \quad \underset{\mathrm{MW}}{\mathrm{H}}:=1.38 \quad \mathrm{Z}:=16 \quad \mathrm{Spr}:=150 \\
\mathrm{~B}:=40 \quad \mathrm{tpr}:=0.01
\end{array} \\
& \mathrm{Pz}:=2.254 \frac{\mathrm{Gt}^{0.342} \cdot \mathrm{H}^{0.258} \cdot \mathrm{Vpop}^{0.945}}{\mathrm{Z}^{0.051} \cdot \mathrm{Vz}^{0.073} \cdot \mathrm{Spr}^{0.073} \cdot \mathrm{tpr}^{0.026}} \cdot \mathrm{B} \quad \mathrm{Pz}=485.251 \quad \underset{\mathrm{M}}{\mathrm{N}}:=\frac{\mathrm{Pz} \mathrm{Vz}}{60}=808.751 \\
& \mathrm{Hd}=0.049 \quad \mathrm{n} 1:=8 \quad \ddot{\mathrm{I}} 1:=\sum_{\mathrm{i}=1}^{\mathrm{n} 1}\left[\mathrm{So} \cdot\left(1-\mathrm{k}^{\mathrm{i}}\right)+\mathrm{S} 10 \mathrm{k} \mathrm{k}^{\mathrm{i}}\right] \quad \ddot{\mathrm{I}} 1=0.052 \\
& \begin{array}{l}
\ddot{\mathrm{I}} 2:=\ddot{\mathrm{I}}-\ddot{\mathrm{I}} 1=0.148 \quad \mathrm{n} 2:=16 \quad \ddot{\mathrm{I}} 3:=\sum_{\mathrm{i}=1}^{\mathrm{n} 2}[\mathrm{~S} 1 \mathrm{o}(1-\mathrm{k})] \quad \ddot{\mathrm{i}} 3=0.155 \\
\mathrm{n}:=\mathrm{n} 1+\mathrm{n} 2=24
\end{array} \\
& \text { To }:=\frac{\pi \cdot d z \cdot 60}{V_{z} \cdot 1000} \cdot \mathrm{n} \quad \mathrm{To}_{0}=4.524
\end{aligned}
$$

Fig. 4. The choice of the optimal value of the roughing feed $S_{10}$ for the CPGC at $S=V_{z}=100 \mathrm{~m} / \mathrm{min}$

In Fig. 4, the calculation is given for $S_{10}=0.012 \mathrm{~mm}$, which corresponds to the third step of selection $S_{10}$ according to the Tab. 1 .

Table 1. Selection of the optimal value $S_{10}$ when $S=V_{z}=100 \mathrm{~m} / \mathrm{min} \mathrm{m} / \mathrm{min}$

\begin{tabular}{|c|c|c|c|c|c|c|c|c|}
\hline $\begin{array}{c}\text { No step } \\
\text { selection }\end{array}$ & $\begin{array}{c}S_{10}, \\
\mathrm{~mm}\end{array}$ & $\begin{array}{c}V_{p}, \\
\mathrm{~mm} / \mathrm{min}\end{array}$ & $\begin{array}{c}H_{d}, \\
\mathrm{~mm}\end{array}$ & $n_{1}$ & $n_{2}$ & $n$ & $\begin{array}{c}P_{z}, \\
\mathrm{~N}\end{array}$ & $\begin{array}{c}N \\
\mathrm{~W}\end{array}$ \\
\hline 1 & 0.007 & 2.23 & 0.023 & 5 & 28 & 33 & 291 & 485 \\
\hline 2 & 0.01 & 3.183 & 0.041 & 7 & 19 & 26 & 408 & 680 \\
\hline 3 & 0.012 & 3.82 & 0.05 & 8 & 16 & 24 & 485 & 808 \\
\hline 4 & 0.013 & 4.138 & 0.055 & 8 & 14 & 22 & 523 & 872 \\
\hline
\end{tabular}

The optimal value $S_{10}$ corresponds to the third step of its appointment. The fourth step $S_{10}=0.013$ provides higher productivity, but the power $N$ consumed by the drive rotates the workpiece equal to $872 \mathrm{~W}$ more than the nominal, which is unacceptable.

Thus, setting $V_{p}=3.82 \mathrm{~mm} / \mathrm{min}, \quad S=100 \mathrm{~m} / \mathrm{min}$ when implementing a two-stage plunge grinding cycle with a restriction on heating the part no higher than $490^{\circ} \mathrm{C}$, the main grinding time $T_{0}=4.572 \mathrm{~s}$.

A similar search for optimal conditions for plunge grinding is performed for $S=V_{z}=35 \mathrm{~m} / \mathrm{min}$ and its results are summarized in the Tab. 2.

Table 2. Selection of the optimal value $S_{10}$ when $S=V_{z}=35 \mathrm{~m} / \mathrm{min}$

\begin{tabular}{|c|c|c|c|c|c|c|c|c|}
\hline $\begin{array}{c}\text { No } \\
\text { step } \\
\begin{array}{r}\text { selec- } \\
\text { tion }\end{array}\end{array}$ & $\begin{array}{c}S_{10}, \\
\mathrm{~mm}\end{array}$ & $\begin{array}{c}V_{p}, \\
\mathrm{~mm} / \mathrm{min}\end{array}$ & $\begin{array}{c}H_{d}, \\
\mathrm{~mm}\end{array}$ & $n_{1}$ & $n_{2}$ & $n$ & $\begin{array}{c}P_{z}, \\
\mathrm{~N}\end{array}$ & $\begin{array}{c}N, \\
\mathrm{~W}\end{array}$ \\
\hline 1 & 0.01 & 1.114 & 0.031 & 5 & 18 & 24 & 163.5 & 95 \\
\hline 2 & 0.015 & 1.671 & 0.062 & 9 & 11 & 20 & 239.8 & 139.9 \\
\hline 3 & 0.02 & 2.228 & 0.09 & 12 & 7 & 19 & 314.8 & 183.6 \\
\hline 4 & 0.025 & 2.785 & 0.116 & 16 & 5 & 21 & 388.7 & 226 \\
\hline
\end{tabular}


From table 2 it is seen that the optimal grinding conditions with $S=V_{z}=35 \mathrm{~m} / \mathrm{min}$ correspond to $S_{10}=0.02 \mathrm{~mm} / \mathrm{rev}$ or $V_{p}=2.228 \mathrm{~mm} / \mathrm{min}$. Thus grinding with a high speed of the workpiece rotation $S=100 \mathrm{~m} / \mathrm{min}$ compared to grinding with the recommended $S=35 \mathrm{~m} / \mathrm{min}$ [48] provides a performance 2 times higher with the restriction on heating the part no more than $490^{\circ} \mathrm{C}$.

The high speed of the workpiece rotation during CPGS not only provides an increase in processing productivity while limiting its maximum permissible heating temperature polished surface $T_{\max }$ but also a lower feed per revolution at this temperature (see the values in the first row of the second columns of the matrices $X$ and $X_{2}$ in Fig. 3).

So at $V_{z}=100 \mathrm{~m} / \mathrm{min} T_{\max }=490^{\circ} \mathrm{C}$ is provided at $S_{0}=0.0035 \mathrm{~mm}$, and at $V_{z}=35 \mathrm{~m} / \mathrm{min}$ the same temperature will be reached if $S_{0}=0.006 \mathrm{~mm}$.

It is known that it is precisely the reduction in feed per revolution (grinding depth), which is achieved, for example, in the sparking-out phase during CPGS, which ensures the smallest surface roughness.

Therefore, CPGS with a high speed of the workpiece rotation is preferable when compared with grinding at a lower speed of the workpiece rotation and for achieving a small surface roughness. CPGS with less feed per revolution also forms less out of roundness of the cylindric surface of the part.

In the preceding studies, the processing of a cylindric surface along an axis length of $40 \mathrm{~mm}$ was analyzed, while grinding wheels with a height of $80 \mathrm{~mm}$ were used on the 3M151 grinding machine. This limitation of the surface length in 40 millimeters is due to the rotation drive power for the workpiece revolution, the nominal value of which for a $3 \mathrm{M} 151$ grinding machine is $850 \mathrm{~W}$. For grinding with a high speed of the workpiece revolution, for example, equal to $100 \mathrm{~m} / \mathrm{min}$, a surface length of $80 \mathrm{~mm}$ requires an increase in drive power by about two times.

\section{CONCLUSIONS}

Mathematical modelling for calculating the optimal cutting conditions during cylindrical plunge grinding with a view to minimizing the depth of the defective layer formed by the temperature in the contact zone of the grinding wheel and the workpiece was carried out. Modelling results show next:

1. The high speed of the workpiece rotation provides a smaller depth of the defective layer depending on the size of the cross-feed motion $V_{p}$.

2. The use of the plunge grinding cycle with a high peripheral speed of the workpiece rotation $S$, for example, equal to $100 \mathrm{~m} / \mathrm{min}$, allows reducing the main operation time by 2 times with defect- free processing, according to the temperature criteria.

3. All indicators of the machining quality using CPGS both physical and mechanical and geometric (roughness, out-of-roundness) are achieved at higher productivity if grinding is carried out at a high speed of the workpiece rotation.

\section{REFERENCES}

1. Ivanov V, Dehtiarov I, Pavlenko I, Kosov I, Kosov M. Technology for complex parts machining in multiproduct manufacturing. Management and Production Engineering Review 2019; 10(2): 25-36. https://doi.org/10.24425/mper.2019.129566.

2. Karpus V, Dehtiarov I, Zajac J, Kurochkina V. Technological assurance of complex parts manufacturing. In: Ivanov V. et al. eds. Advances in Design, Simulation and Manufacturing. DSMIE 2018. 1st ed. Lecture Notes in Mechanical Engineering: Springer, Cham; 2019. https://doi.org/10.1007/978-3-319-93587-4 6

3. Denysenko Y, Dynnyk O, Yashyna T, Malovana N, Zaloga V. Implementation of CALS-Technologies in quality management of product life cycle processes. In: Ivanov V. et al. eds. Advances in Design, Simulation and Manufacturing. DSMIE 2018. 1st ed. Lecture Notes in Mechanical Engineering: Springer, Cham; 2019. https://doi.org/10.1007/978-3-31993587-4_1

4. Dynnyk O, Denysenko Y, Zaloga V, Ivchenko O, Yashyna T. Information support for the quality management system assessment of engineering enterprises. In: Ivanov V. et al. eds. Advances in Design, Simulation and Manufacturing II. DSMIE 2019. 1st ed. Lecture Notes in Mechanical Engineering. Springer, Cham; 2020. https://doi.org/10.1007/978-3-030-22365-6_7

5. Yarovyi Y, Yarova I. Energy Criterion for Metal Machining Methods. In: Ivanov V. et al. eds. Advances in Design, Simulation and Manufacturing II. DSMIE 2019. 1st ed. Lecture Notes in Mechanical Engineering. Springer, Cham; 2020. https://doi.org/10.1007/978-3-030-22365-6_38

6. Fesenko A, Basova $\mathrm{Y}$, Ivanov $\mathrm{V}$, Ivanova $\mathrm{M}$, Yevsiukova F, Gasanov M. Increasing of equipment efficiency by intensification of technological processes. Periodica Polytechnica Mechanical Engineering 2019; 63(1): 67-73. https://doi.org/10.3311/PPme.13198

7. Krol O, Sokolov V. Development of models and research into tooling for machining centers. EasternEuropean Journal of Enterprise Technologies 2018; 3(1-93): 12-22. $\quad$ https://doi.org/10.15587/17294061.2018.131778

8. Sokolov V, Krol O. Determination of transfer functions for electrohydraulic servo drive of technological equipment. In: Ivanov V. et al. (eds) Advances in Design, Simulation and Manufacturing. DSMIE 2018. Lecture Notes in Mechanical Engineering. Springer, Cham; 2019. https://doi.org/10.1007/978-3-319-93587-4_38

9. Denkena B, Gümmer O. Active tailstock for precise alignment of precision forged crankshafts during grinding. Procedia CIRP 2013; 12: 121-126. https://doi.org/10.1016/j.procir.2013.09.022 
10. Dražumerič R, Roininen R, Badger J, Peter K. Temperature-based method for determination of feed increments in crankshaft grinding. Journal of Materials Processing Technology 2018; 259: 228234. https://doi.org/10.1016/j.jmatprotec.2018.04.032

11. Xu XL, Yu ZW. Failure analysis of a truck diesel engine crankshaft. Engineering Failure Analysis 2018;92:84-94. https://doi.org/10.1016/j.engfailanal.2018.05.007

12. Stepanov M, Ivanova L, Litovchenko P, Ivanova M, Basova Y. Determination of parameters of cylindrical grinding with additional intermediate dressing. In: Ivanov V. et al. eds. Advances in Design, Simulation and Manufacturing II. DSMIE 2019. Lecture Notes in Mechanical Engineering. Springer, Cham; 2020. https://doi.org/10.1007/978-3-030-22365-6_33

13. Belkhode PN. Optimum choice of the front suspension of an automobile. Journal of Engineering Sciences 2019;6(1):E21-E24. https://doi.org/10.21272/jes.2019.6(1).e4

14. Kotliar A, Basova Y, Ivanova M, Gasanov M, Sazhniev I. Technological assurance of machining accuracy of crankshaft. In: Diering M., Wieczorowski M., Brown C. eds. Advances in Manufacturing II. MANUFACTURING 2019. Lecture Notes in Mechanical Engineering. Springer, Cham; 2019. https://doi.org/10.1007/978-3-030-18682-1_4

15. Kostyuk G. Prediction of the microhardness characteristics, the removable material volume for the durability period, cutting tools durability and processing productivity depending on the grain size of the coating or cutting tool base material. In: Gapiński B., Szostak M., Ivanov V. (eds) Advances in Manufacturing II. MANUFACTURING 2019. Lecture Notes in Mechanical Engineering. Springer, Cham; 2019. https://doi.org/10.1007/978-3-03016943-5_27

16. Kostyuk G, Nechyporuk M, Kostyk K. Determination of technological parameters for obtaining nanostructures under pulse laser radiation on steel of drone engine parts. In 10th International Conference on Dependable Systems, Services and Technologies, DESSERT 2019. Institute of Electrical and Electronics Engineers Inc; 2019. https://doi.org/10.1109/DESSERT.2019.8770053

17. Tarelnyk V., Konoplianchenko I., Tarelnyk N., Kozachenko A. Modeling technological parameters for producing combined electrospark deposition coatings. Materials Science Forum 2019; 968: 131142 .

https://doi.org/10.4028/www.scientific.net/MSF.968.131

18. Martsynkovskyy V, Tarelnyk V, Konoplianchenko I, Gaponova O, Dumanchuk M. Technology support for protecting contacting surfaces of half-couplingshaft press joints against fretting wear. In: Ivanov V. et al. (eds) Advances in design, simulation and manufacturing II. DSMIE 2019. Lecture Notes in Mechanical Engineering. Springer, Cham; 2020. https://doi.org/10.1007/978-3-030-2236

19. Basova Y, Nutsubidze K, Ivanova M, Slipchenko S, Kotliar A. Design and numerical simulation of the new design of the gripper for manipulating of the rotational parts. Diagnostyka 2018;19(4):11-18. https://doi.org/10.29354/diag/94030

20. Karpus VE, Ivanov VA. Locating accuracy of shafts in vblocks. Russian Engineering Research 2012; 32(2):144-150.

https://doi.org/10.3103/S1068798X1202013X
21. Jaeger JC. Moving source of heat and temperature at sliding contact. Proceeding the Royal Society of NSW 1942; 76: 203-224.

22. Karslou H, Eher D. Thermal conductivity of solids. 1st ed. Moscow: Nauka, 1964. Russian.

23. Sypailov AV. Grinding thermal processes and surface quality control. 1st ed. Moscow: Mashynostroenye, 1978. Russian.

24. Yakymov AV, Tkachenko VO, Zymyn SH, Yakymov AA, Novykov FV, Novykov HV. Thermal processes during normal and intermittent grinding: tutorial. In 5 books. 1st ed. Odessa: Odessa state polytechnic University, 1998. Russian.

25. Korchak SN. Advanced technology and automation for circular grinding. 1st ed Moscow: Mashynostroenye, 1968. Russian.

26. Peznykov AN. Thermophysics of cutting. 1st ed. Moscow: Mashynostroenye, 1969. Russian.

27. Redko SH. Heat generation processes during grinding of metals. 1st ed. Saratov: Saratovskoho unyversyteta, 1962. Russian.

28. Ostrovskyi VI. The theoretical basis of the grinding process. 1st ed. Lenynhrad: Lenynhradskoho unyversyteta, 1981. Russian.

29. Byshutyn SH. Providing the required set of quality parameters for the surface layers of the part during grinding. 1st ed. Moscow: Mashynostroenye, 2004. Russian.

30. Byshutyn SH, Tiulpanov NV. Prediction of heat in the contact zone of the workpiece and grinding wheel, taking into account its wear [Prohnozyrovanye teplovidelenyia $\mathrm{v}$ kontaktnoi zone zahotovky y shlyfovalnoho kruha s uchetom eho yznashyvanyia]. Bulletin of the Bryansk State Technical University 2007; 2(14): 4-9. Russian.

31. Maslov EN. Theory of grinding materials. 1st ed. Moscow: Mashynostroenye, 1974. Russian.

32. Lure HB. Grinding metals. 1st ed. Moscow: Mashynostroenye, 1969. Russian.

33. Fulumonov LN. High speed grinding. 1st ed. Lenynhrad: Mashynostroenye, 1979. Russian.

34. Bratan S, Bogutsky B, Roshchupkin S. Development of mathematical model of material removal calculation for combined grinding process. In: Radionov A., Kravchenko O., Guzeev V., Rozhdestvenskiy Y. (eds). Proceedings of the 4th International Conference on Industrial Engineering. ICIE 2018. Lecture Notes in Mechanical Engineering. Springer, Cham; 2019. https://doi.org/10.1007/978-3-319-95630-5_189

35. Bratan S, Roshchupkin S, Revenko D. Probabilistic approach for modeling electroerosion removal of grinding wheel bond. Procedia Engineering 2017; 206:1426-1431.

https://doi.org/10.1016/j.proeng.2017.10.656

36. Soler YI, Mai DS, Kazimirov DY. Contact ability optimization of the surface of titanium parts with different stiffness during flat grinding by highly porous wheel. In: International Conference on Modern Trends in Manufacturing Technologies and Equipment, ICMTMTE 2018; 224: 01062. Irkutsk, Russian Federation; 2018. https://doi.org/10.1051/matecconf/201822401062

37. Bogutsky V, Novoselov Y, Shron L. Calculating the profile of intermittent grinding wheel for the sharpening teeth of the broach. In: MATEC Web of Conferences. 2018 International Conference on 
Modern Trends in Manufacturing Technologies and Equipment, ICMTMTE 2018; 224: 01003. Sevastopol, Russian Federation; 2018 https://doi.org/10.1051/matecconf/201822401003

38. Yin G, Gong Y, Wang C, Cui Q. Study on effects of novel point grinding wheels processing parameters on grinding temperature. Zhongguo Jixie Gongcheng/China Mechanical Engineering 2015; 26(6): 716-720. https://doi.org/10.3969/j.issn.1004132X.2015.06.002

39. Qian N, Fu Y, Zhang Y, Chen J, Xu J. Experimental investigation of thermal performance of the oscillating heat pipe for the grinding wheel. International Journal of Heat and Mass Transfer, 2019;136:911-923. https://doi.org/10.1016/j.ijheatmasstransfer.2019.03.065

40. Smirnov VA, Repko AV. Workpiece temperature variations during flat peripheral grinding. Management Systems in Production Engineering 2018; 26(2): 93-98. https://doi.org/10.1515/mspe2018-0015

41. Levin ML, Khudolei AL. Heat Transfer in the Course of Magnetorheological Polishing. Journal of Engineering Physics and Thermophysics 2018; 91(3): 797-805. https://doi.org/10.1007/s10891-0181802-3

42. Dement VB, Ivanova TN, Dolginov AM. Temperature of heating and cooling of massive, thin, and wedge-shaped plates from hard-to-machine steels during their grinding. Journal of Engineering Physics and Thermophysics 2017; 90(1): 102-109. https://doi.org/10.1007/s10891-017-1544-7

43. Zhu C., Gong L, Tie S-N. Influence of preparation processes on thermophysical properties of molten salt. AIP Advances 2020; 10(2): 025214. https://doi.org/10.1063/1.5129609

44. Novykov FV. A mathematical model for determining the grinding temperature based on the balance of heat leaving in the generated chips and the workpiece. [Matematycheskaia model opredelenyia temperaturb shlyfovanyia na osnove ucheta balansa tepla, ukhodiashcheho $\mathrm{v}$ obrazuiushchyesia struzhky y obrabatovaemuiu detal]. Bulletin of the National Technical University of Agriculture. P. Vasilenko 2007; 61: 22-33. Russian.

45. Novykov FV, Riabenkov IA. Theoretical analysis of conditions for improving the quality of processing according to the temperature criterion [Teoretycheskyi analyz uslovyi povishenyia kachestva obrabotky po temperaturnomu kryteryiu]. Bulletin of the National Technical University of Agriculture. P. Vasilenko 2007; 61: 164-171. Russian.

46. Syzyi YuA, Stalinskyi DV. The dynamics and thermal physics of grinding. 1st ed. Kharkiv: SE «UkrSTC Energostal», 2016. Russian.

47. Reference technologist-machine builder. In two volumes. In: Kosylov AH, Meshcheriakov RK eds. 1st ed. Vol.I. Moscow: Mashynostroenye, 1985. Russian.

48. Reference technologist-machine builder. In two volumes. In: Kosylov AH, Meshcheriakov RK eds. 1st ed. Vol.II. Moscow: Mashynostroenye, 1985. Russian.

Received 2020-02-26

Accepted 2020-05-18

Available online 2020-05-20

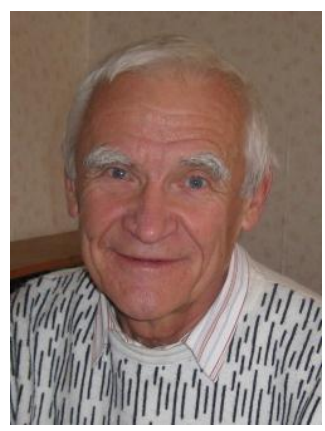

Yurii SYZYI, doctor of sciences, Professor at the Department of technology of mechanical engineering and metal-cutting machine tools of the Educational and scientific institute of mechanical engineering and transport of the NTU "KhPI", Kharkov, Ukraine.

Main directions of scientific research: enhancement of functional capabilities and an increase productivity metalcutting machines; multi-criteria optimization of technological processes and systems, grinding process dynamics.

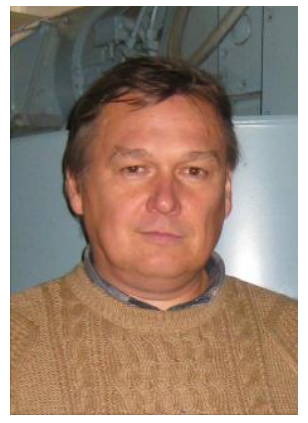

Oleksandr USHAKOV, $\mathrm{PhD}$, Associate Professor at the Department of technology of mechanical engineering and metal-cutting machine tools of the Educational and scientific institute of mechanical engineering and transport of the NTU "KhPI", Kharkov, Ukraine.

Main directions of scientific research: enhancement of functional capabilities and an increase productivity metalcutting machines; multi-criteria optimization of technological processes and systems, grinding process dynamics.

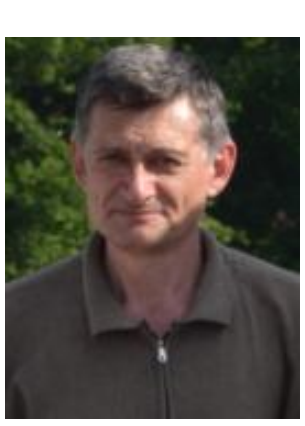

Serhii SLIPCHENKO (ORCID 0000-0003-05933750), Senior Lecturer at the Department of technology of mechanical engineering and metal-cutting machine tools of the Educational and scientific institute of mechanical engineering and transport of the NTU "KhPI", Kharkov, Ukraine.

Main directions of scientific research: enhancement of functional capabilities and an increase productivity metal-cutting machines; multicriteria optimization of technological processes and systems.

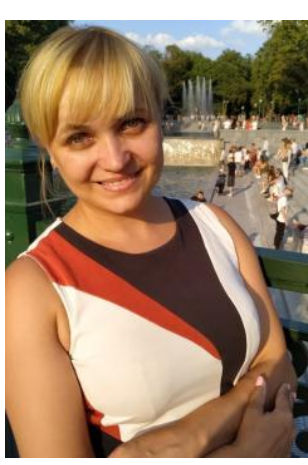

Yevheniia BASOVA (ORCID 0000-0002-8549-4788), PhD, Associate Professor at the Department of technology of mechanical engineering and metal-cutting machine tools of the Educational and scientific institute of mechanical engineering and transport of the NTU "KhPI", Kharkov, Ukraine.

Main directions of scientific research: physicotechnical processing methods, engineering technology, programming, CAD / CAM / CAE / CAPP systems, optimization and modelling in mechanical engineering 
processes for technological prognostication in innovations, Industry 4.0.

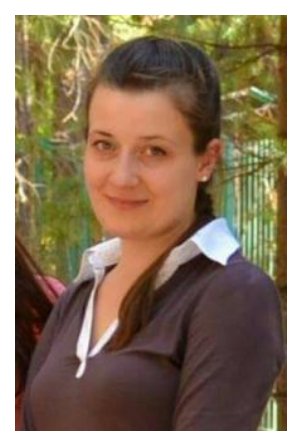

Maryna IVANOVA (ORCID

0000-0002-0848-6805), $\mathrm{PhD}$,

Associate Professor at the

Department of technology of mechanical engineering and metal-cutting machine tools of the Educational and scientific institute of mechanical engineering and transport of the NTU “KhPI”, Kharkov, Ukraine.

Main directions of scientific functional capabilities and an increase productivity metalcutting machines; multi-criteria optimization of technological processes and systems. 